\title{
Real-time species distribution models for conservation and management of natural resources in marine environments
}

\author{
Henrik Skov ${ }^{1, *}$, Stefan Heinänen' ${ }^{1}$, Chris B. Thaxter ${ }^{2}$, Adrian E. Williams $^{3}$, \\ Sabine Lohier ${ }^{1}$, Alex N. Banks ${ }^{3}$ \\ ${ }^{1}$ DHI, Agern Alle 5, 2970 Hørsholm, Denmark \\ ${ }^{2}$ British Trust for Ornithology, The Nunnery, Thetford IP24 2PU, UK \\ ${ }^{3}$ APEM Ltd., Riverview, A17 Embankment Business Park, Heaton Mersey, Stockport SK4 3GN, UK
}

\begin{abstract}
Species distribution models in marine environments typically use static variables, partly due to the limited availability of fine-resolution dynamic predictor variables and sufficiently detailed species abundance data. Our aim was to describe and quantify the dynamic coupling between the distribution of marine species (seabirds) and the natural variability of their habitat in real time through the combination of a high-resolution hydrodynamic model, aerial digital surveys and real-time species distribution modelling. We used a 2-step (delta) generalized additive model at $500 \mathrm{~m}$ spatial resolution for assessment and prediction of the changing patterns of wintering red-throated divers (RTDs) Gavia stellata in the outer Thames estuary, United Kingdom. Our dynamic species distribution models successfully resolved the major oscillations in the distribution of RTDs and confirmed their tight association with frontal zones where the probability of prey encounter was higher. The relative model standard errors (\%) were generally below $30 \%$ in the high-density areas. Area under the curve (AUC) values indicated that the models were capable of distinguishing presence from absence about $75 \%$ of the time. The predictive power of the achieved distribution models made it possible to accurately identify areas where RTDs were concentrated. Comparisons between visual aerial and digital stills aerial surveys documented that, in spite of similar patterns, the aerial digital surveys generally recorded significantly higher densities of RTDs than the visual aerial surveys. This study demonstrates how marine distribution models with assimilation of habitat variables from a well-calibrated fine-resolution hydrodynamic model coupled with the use of digital aerial surveys can facilitate the capture of detailed associations between seabirds and their dynamic habitats.
\end{abstract}

KEY WORDS: Digital stills aerial surveys - Dynamic species distribution models $\cdot$ Hydrodynamic models $\cdot$ Marine spatial planning $\cdot$ Offshore wind farms $\cdot$ Red-throated diver $\cdot$ Visual aerial surveys

\section{INTRODUCTION}

The global predicted energy capacity from offshore wind is expected to increase from $9 \mathrm{GW}$ at present to 25 GW by 2020 (reNews 2014). This large-scale increase in infrastructures in shallow shelf seas has the potential to cause environmental impacts, which may include long-term habitat displacements of cer-

*Corresponding author: hsk@dhigroup.com tain species of seabirds and marine mammals (Fox et al. 2006). Within environmental impact assessments, studies of habitat displacement may preferably be undertaken using model-based methods such as investigating the effects on demographic parameters, or relating shifts of distribution of animals to both the displacement and natural habitat changes (Buckland et al. 2012). The use of predictive distribution models

(C) The authors 2016. Open Access under Creative Commons by Attribution Licence. Use, distribution and reproduction are unrestricted. Authors and original publication must be credited. 
has increased dramatically over the past $20 \mathrm{yr}$ and they have been applied in a number of terrestrial studies aimed at describing and understanding the distribution of species at various spatial scales (Guisan \& Zimmermann 2000, Elith et al. 2006). In comparison, relatively few applications of predictive distribution models have been realised in the marine environment (Robinson et al. 2011, Skov et al. 2014). Pendleton et al. (2012) modelled the weekly probability of occurrence of the North Atlantic right whale Eubalaena glacialis in the Gulf of Maine based on prey and oceanographic variables; and Skov et al. (2014) modelled the distribution of the harbour porpoise Phocoena phocoena in the German Bight during different current scenarios defined by estuarine and tidal dynamics. However, the majority of other marine studies have been made at a relatively coarse resolution and covering relatively large extents (Bailey \& Thompson 2009, Maxwell et al. 2009).

Terrestrial applications of distribution models typically assume that the physical environment exerts a dominant control over the natural distribution of a species. Obviously, the transfer of distribution models from land to sea means that the validity of model assumptions and predictive performance will be affected by the unique physical properties of marine habitats (Robinson et al. 2011). As a consequence, the detailed resolution of the distribution of marine species will require that the dynamic coupling to their physical environment is determined. However, synoptic dynamic data on driving habitat parameters such as currents and hydrographic structures are often very difficult to obtain; the descriptions of key habitat features typically stem from correlations with static parameters such as water depth and distance to land (Skov et al. 2003, MacLeod \& Zuur 2005, Cama et al. 2012). The fine-scale distribution of marine top predators has been shown to correlate with physical oceanographic properties such as fronts, upwellings and eddies, which enhance the probability of predators encountering prey (Schneider \& Duffy 1985, Skov \& Prins 2001, Fauchald et al. 2011) exhibiting spatial dynamics and oscillations at different frequencies.

To accurately describe the distribution of seabirds over time, one needs to be able to take account of the actual habitat components realised during each observation. In the absence of these dynamic characteristics of seabird habitats, static distribution models of seabirds will unlikely resolve the true variation in the distribution of the birds. In other words, if highresolution distribution models are based on static factors or mean values rather than in situ values for dynamic factors, predicted densities will rarely match the observed densities. As a result, the risk exists that assessments of habitat displacement based on static distribution models may lead to a type II error-a result estimating an impact in an area of low seabird density - or a type I error - a result erroneously pointing at a smaller or medium impact in an area where seabirds are highly concentrated. Thus, accurate assessment of habitat displacement of seabirds and other marine top predators remains a challenge, due to the need for highly dynamic, fine-resolution data both for species and the environment. Likewise, the application of static rather than dynamic distribution models in studies aiming at identifying candidate marine protected areas may result in an overestimate of densities in the periphery of species aggregations and an underestimate of densities within aggregations, leading to less accurate area designations.

Here, we investigate the potential for achieving a high predictive accuracy in distribution models of the red-throated diver (RTD) Gavia stellata in offshore areas by integrating high-resolution hydrodynamic models with aerial survey data of the RTD, which overwinters in large numbers in the outer Thames estuary (Fig. 1). The outer Thames estuary is heavily influenced by tidal currents and is a highly dynamic physical environment, making this an ideal study system for investigating changes in distribution in relation to dynamic habitat states. Furthermore, we explored the use of visual aerial surveys and digital high-definition imagery (individual still photographs) to parameterise the distribution models. This study therefore provided a useful opportunity to compare aerial survey methods and particularly to test the digital aerial survey method for its potential in improving the accuracy of marine distribution models.

\section{MATERIALS AND METHODS}

\section{Study area and survey methodology}

Two aerial survey methods were used - visual and digital stills. Visual survey data were collected using standard protocols during the winters 2003-2004, 2004-2005, 2005-2006 and 2009-2010. Digital stills survey data were collected during the winters 2009-2010 and 2010-2011. Although considerable coverage was achieved by the aerial surveys, it is clear that the coverage was rather uneven (see Fig. S1 in the Supplement at www.int-res.com/articles/ suppl/m542p221_supp.pdf; Table 1). Visual aerial 
Table 1. Survey statistics for (a) visual and (b) digital stills aerial surveys. Given are the transect total length, number of redthroated divers (RTDs) Gavia stellata observed in the transect per survey winter, the ranges of the daily mean, variance-tomean $\left(\mathrm{s}^{2} / \overline{\mathrm{X}}\right)$ ratio, skewness and kurtosis values and the results of Shapiro-Wilks $W$ tests of normality. All survey $W$ statistics except one (Visual 2009-2010) were significant $(\mathrm{p}<0.001)$

\begin{tabular}{|c|c|c|c|c|c|c|c|}
\hline $\begin{array}{l}\text { Survey } \\
\text { winter }\end{array}$ & $\begin{array}{c}\text { Transect } \\
\text { length }(\mathrm{km})\end{array}$ & $\begin{array}{c}\text { No. of } \\
\text { observed RTDs }\end{array}$ & $\bar{X} /$ count unit & $\mathrm{S}^{2} / \overline{\mathrm{X}}$ ratio & Skewness & Kurtosis & $W$ \\
\hline \multicolumn{8}{|l|}{ (a) Visual } \\
\hline 2003-2004 & 4004.9 & 3243 & $0.03-1.22$ & $1.42-79.61$ & $5.24-21.21$ & $38.62-563.89$ & $0.09-0.35$ \\
\hline 2004-2005 & 9287.1 & 2070 & $0.01-0.17$ & $0.99-17.27$ & $6.06-28.55$ & $50.11-967.09$ & $0.02-0.30$ \\
\hline 2005-2006 & 5035.1 & 1947 & $0.03-0.17$ & $1.12-12.58$ & $5.23-28.41$ & $41.25-1084.20$ & $0.07-0.34$ \\
\hline 2009-2010 & 2170.2 & 734 & $0.16-2.74$ & $1.25-12.58$ & $1.24-7.61$ & $1.2-63.88$ & $0.18-0.87$ \\
\hline \multicolumn{8}{|c|}{ (b) Digital stills } \\
\hline $2009-2010$ & 5011.5 & 379 & $0.012-0.36$ & $0.53-5.76$ & $3.64-21.96$ & $14.8-674.79$ & $0.25-0.41$ \\
\hline 2010-2011 & 12738.8 & 2065 & $0.007-0.35$ & $1.39-10.34$ & $8.26-17.26$ & $107.54-361.48$ & $0.044-0.21$ \\
\hline
\end{tabular}

surveys were undertaken along evenly spaced transects and RTDs were recorded in segments of $300 \mathrm{~m}$ length and allocated into predefined distance bands. This methodology allowed for distance correction of the decrease in detectability of RTDs away from the plane. The digital survey method, using highresolution still-imagery cameras, required different survey protocols from traditional visual methods, because it did not employ the counting of birds within defined distance intervals away from an aircraft, but instead one or more cameras surveyed a 'quadrat' immediately below the aircraft (Buckland et al. 2012). Contrary to the situation during visual aerial surveys, it is assumed that all birds are detected, hence no distance correction is needed. The digital stills data used in this study are still images that were taken as planes crossed predefined equally

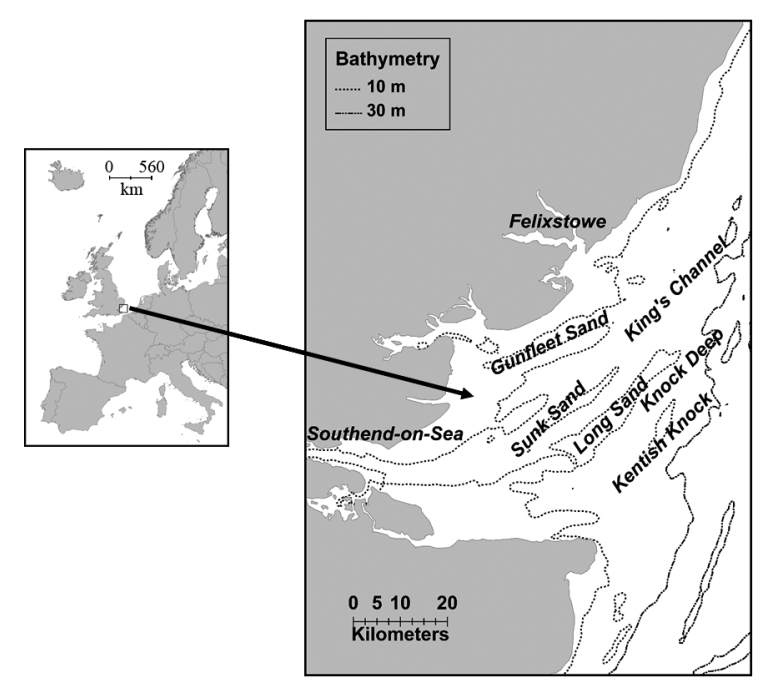

Fig. 1. Study area. The bathymetry and bathymetric features frequently referred to in the text are indicated spaced GPS reference points. Thus, a grid of images across the survey area was obtained for each survey. In order to compare the numbers recorded and distribution obtained from the 2 methods, comparative surveys were conducted for 4 mo during the winter of 2009-2010 (Table 1b, Fig. S1 in the Supplement). The digital stills aerial surveys generally covered the same extent of the study region as that of the visual aerial surveys but, due to the reasons described above, a smaller total area.

\section{Modelling setup}

An overview of the model design developed to predict densities of RTD is given in Fig. 2. The model design was composed of a hydrodynamic model frame-

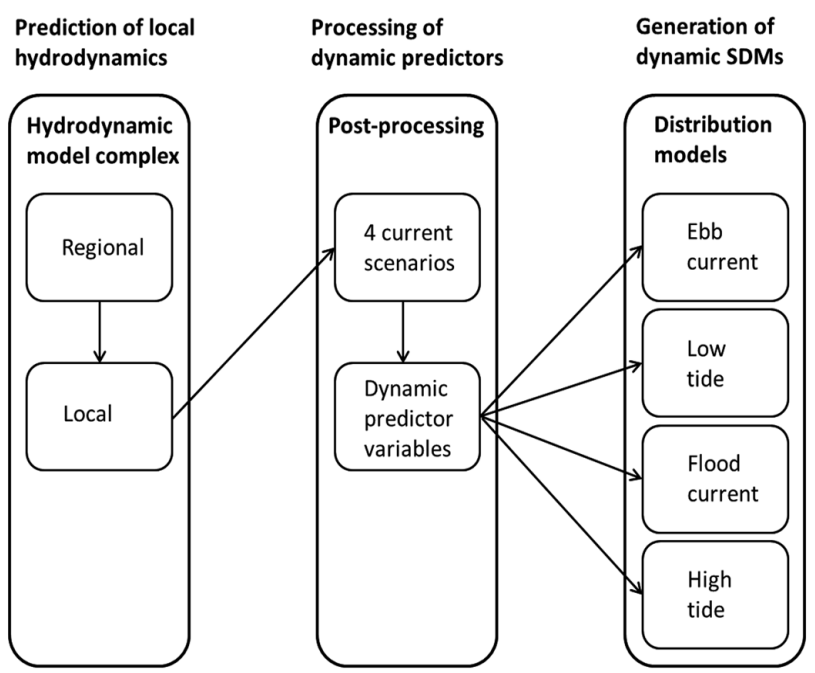

Fig. 2. Design used for the generation of the dynamic distribution models (SDMs) for red-throated divers (RTDs) Gavia stellata 
work consisting of a regional and a local model, postprocessing chains extracting dynamic habitat variables for 4 tidal current scenarios and distribution models covering each scenario and describing statistical responses of observed RTDs to the habitat variables.

\section{Hydrodynamic model}

We designed a local fine-scale hydrodynamic model to include boundary conditions from a regional model covering all RTD survey periods. The model computed salinity, temperature, current speed and direction at $1 \mathrm{~h}$ temporal resolution, and $500 \mathrm{~m}$ spatial resolution, for the period 2004 to 2012 . To derive biologically meaningful predictors from these, we post-processed them into habitat-describing variables (Table S1 in the Supplement). Local and regional tide gauge and current measurements were used both for data assimilation and validation. Data assimilation improves the skill and accuracy of the hydrodynamic model. This allowed the model accuracy to be greatly improved also at non-observed positions and for additional variables such as the depth-averaged velocity. The data assimilation scheme considered for this project was the steady Kalman filter approach, based on the so-called ensemble Kalman filter. A time-varying, temporally smoothed and distance-regularized ensemble Kalman filter was used with 8 ensemble members.

In addition, the local model integrated river discharge data. The regional hydrodynamic model was set up covering the northwestern part of the Atlantic Ocean and the European northwest shelf with the DHI modelling software MIKE 21 Flexible Mesh HD (Rasmussen 1991), with the purpose of providing accurate boundary conditions to the 3-dimensional (3D) local fine-meshed hydrodynamic model (see also Skov et al. 2014). The latter was forced by tide and wind, and integrated data assimilation following Sørensen et al. (2004). The tidal potential forcing was implemented as an equilibrium tide. Water levels around the project area relied primarily on the interplay between tidal waves propagating along the English Channel and the North Sea. Thus, the regional model was constrained increasingly from upstream to the outer estuary to ensure accurate predictions. A local 3D baroclinic fine-scaled hydrodynamic model was set up with the DHI modelling software MIKE 3 FM HD (Rasmussen 1991), with the purpose of producing a detailed hind-cast of the hydrodynamics of the estuary. The model used an unstructured mesh, enabling a high spatial resolu- tion in focal areas (Fig. 3). The resolution of the horizontal mesh varied from $0.05^{\circ}$ at the boundaries to a mean resolution of $400 \mathrm{~m}$ in the area of the sandbanks. In this area, sandbanks were resolved by triangles with a characteristic length of $200 \mathrm{~m}$, while the channels had a resolution of $600 \mathrm{~m}$. The vertical mesh was discretised by 10 equidistant layers, which was judged sufficiently accurate, as the region is well mixed by the effect of the strong tidal currents.

In order to summarise these dynamics in a plausible way, which would allow a sufficient sample size of RTD observations for the RTD distribution models, the currents in the estuary were classified by a scheme of 4 scenarios. The 4 scenarios represented the dominant hydrodynamic patterns observed (Fig. S2 in the Supplement): (1) developed ebb current directed southwest to northeast; (2) flow reversing (low tide); (3) developed flood current directed northeast to southwest; and (4) flow reversing (high tide).

\section{Distribution models}

In order to describe the spatial distribution and densities of RTDs at the finest spatial and temporal resolution, we applied distribution models coupled to dynamic habitat variables produced by the outer Thames estuary 3D hydrodynamic model at a spatial resolution of $500 \mathrm{~m}$. As sea state can have a large influence on detectability during visual surveys, densities from visual surveys were corrected using detection functions stratified by wave height (thresh-

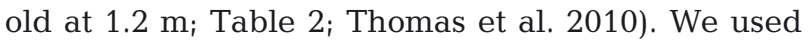
the semi-parametric algorithms of generalized additive models (GAMs; Hastie \& Tibshirani 1990) to enable descriptions of the assumed non-linear relationships between the observed species and the measured environmental predictors.

The environmental variables used to model the diver distribution models were either taken directly from the outer Thames estuary 3D hydrodynamic model or the available topographic, landscape and pressure data layers, or developed through postprocessing of combinations of model simulation results. Diver distribution models from the German Bight and Kattegat have pointed at the importance of frontal features rather than parameters reflecting structures and processes at large scale, like water masses and currents (Skov \& Prins 2001). This is in line with the findings of ubiquitous concentrations of piscivorous species of seabirds at shallow sea fronts (Schneider 1982, Kinder et al. 1983), plume fronts (Skov \& Prins 2001) and shelf break fronts 


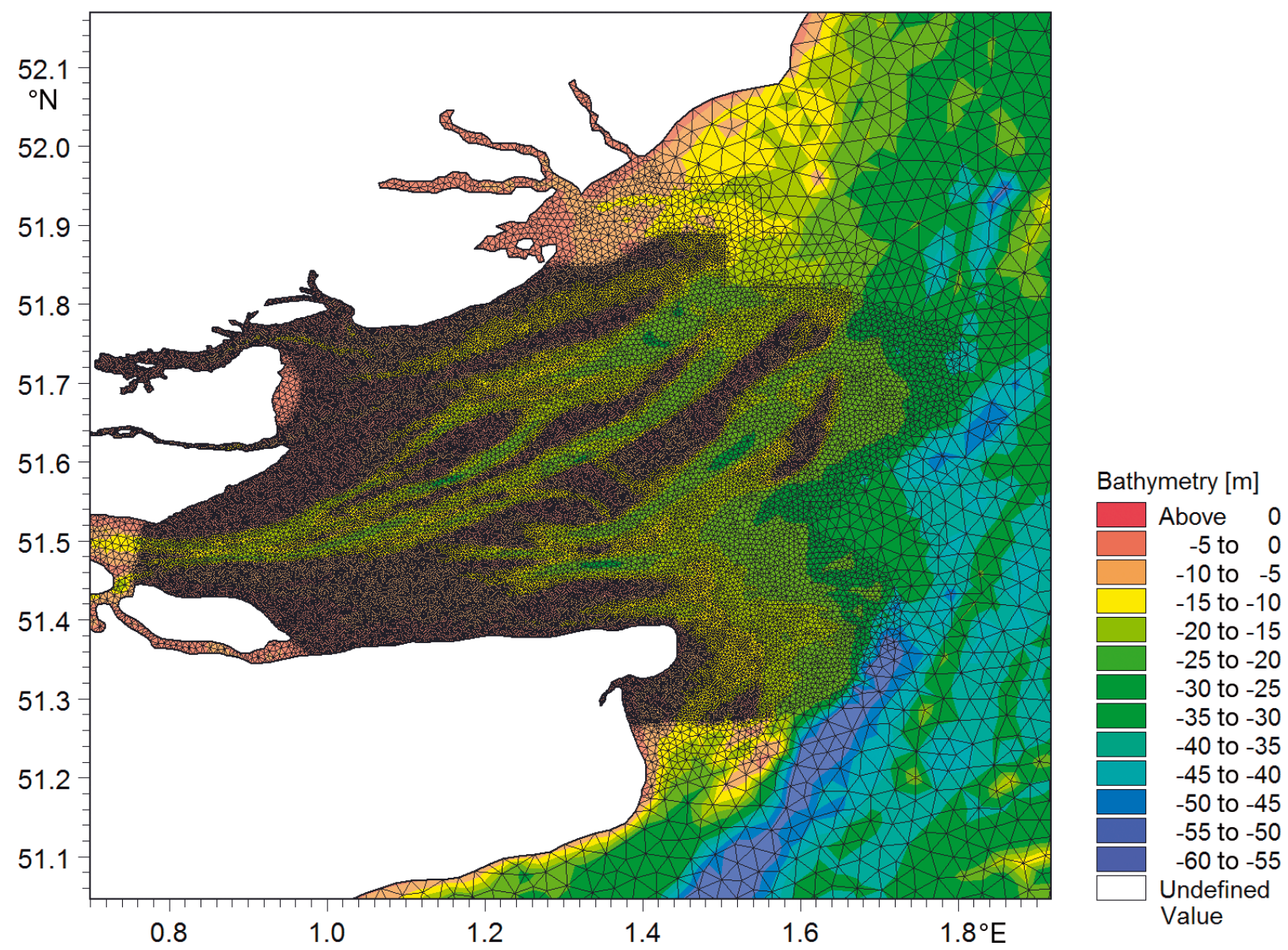

Fig. 3. Horizontal mesh of the local model at the southern part of the outer Thames estuary, showing the bathymetry

(Schneider \& Hunt 1982, Follestad 1990). In the oceanographic context of the outer Thames estuary, these structures may be grouped as horizontal lowfrequency fronts, semi-permanent up/down-welling cells or semi-permanent eddies. The dynamic variables therefore included vertical velocity $(w)$ indicating upwelling activity, current gradient indicating frontal activity and vorticity indicating eddy activity. A complete list of the selected variables used is given in Table S1 in the Supplement.

Owing to an excess of zero counts, the GAM models were fitted using a 2-step approach, a delta model (Le Pape et al. 2004, Potts \& Elith 2006) with a presence/

Table 2. Distance probability functions of observed densities of RTDs; parameters and observation probabilities. ESW: effective strip width

\begin{tabular}{|lccccc|}
\hline Stratum & $\begin{array}{c}\text { Distance } \\
\text { function }\end{array}$ & $\mathrm{f}(0)$ & ESW $(\mathrm{m})$ & $\mathrm{p}$ & $\begin{array}{c}\mathrm{p} \\
(95 \% \mathrm{CI})\end{array}$ \\
\hline Wave height $<1.2 \mathrm{~m}$ & Hazard/cosine & 0.0032897 & 303.98 & 0.30398 & $0.29917-0.30887$ \\
Wave height $\geq 1.2 \mathrm{~m}$ & Hazard/cosine & 0.0044013 & 227.21 & 0.22721 & $0.21554-0.23951$ \\
\hline
\end{tabular}

absence part fitted with a binomial error distribution, and a positive part in which bird density was fitted with a gamma error distribution and a log link (Stefánson 1996). The standard error of the density predictions was calculated using the formula for the variances of the product of 2 random variables (Webley et al. 2011). The models were fitted in $\mathrm{R}$ version 2.9.0 (R Development Core Team 2004) and the package 'mgcv' (Wood 2006) using thin plate regression splines with a smooth function of $5(\mathrm{k}=5)$. The smoothing was not limited for the interaction term between $x$ and $y$-coordinates. Model selection was based on GCV/UBRE scores (Wood \& Augustin 2002), and for reasons of comparability used the same composition of predictor variables for both survey platforms. Predicted densities were grouped into 4 suitability classes using percentiles (90th, 75th, 25th). 
Table 3. Root mean squared errors of the water levels predicted by the $2 \mathrm{D}$ regional model calculated over January 2002 to March 2006. Predictions are compared with measurements from tidal gauge stations

\begin{tabular}{|lcccccc|}
\hline Station & 2002 & 2003 & 2004 & 2005 & $\begin{array}{c}\text { January 2006 to } \\
\text { March 2006 }\end{array}$ & $\begin{array}{c}\text { January 2002 to } \\
\text { March 2006 }\end{array}$ \\
\hline Aberdeen & 0.12 & 0.11 & 0.13 & 0.13 & 0.14 & 0.12 \\
Cherbourg & 0.07 & 0.09 & 0.07 & 0.06 & 0.07 & 0.07 \\
Cromer & 0.06 & 0.05 & 0.05 & 0.06 & 0.06 & 0.06 \\
Devonport & 0.24 & 0.29 & 0.18 & 0.26 & 0.14 & 0.24 \\
Dover & 0.12 & 0.11 & 0.10 & 0.09 & 0.11 & 0.10 \\
Dunkerque & 0.05 & 0.05 & 0.09 & 0.08 & 0.11 & 0.07 \\
Felixstowe & 0.17 & 0.15 & 0.17 & 0.17 & 0.16 & 0.16 \\
Lowestoft & 0.17 & 0.15 & 0.16 & 0.17 & 0.17 & 0.16 \\
Newhaven & 0.06 & 0.04 & 0.08 & 0.07 & 0.10 & 0.06 \\
North Shields & 0.06 & 0.05 & 0.06 & 0.07 & 0.07 & 0.06 \\
Wick & 0.12 & 0.13 & 0.12 & 0.14 & 0.14 & 0.13 \\
\hline
\end{tabular}

Table 4. Root mean squared errors of the water levels and depth-averaged current intensity predicted by the 3D local model calculated over the validation period. Predictions are compared with measurements from tidal gauge stations located within the local model area. -: stations from where no current measurements were available

\begin{tabular}{|lcc|}
\hline Station & $\begin{array}{c}\text { Water level } \\
(\mathrm{m})\end{array}$ & $\begin{array}{c}\text { Current speed } \\
\left(\mathrm{m} \mathrm{s}^{-1}\right)\end{array}$ \\
\hline Felixstowe & 0.228 & - \\
Lowestoft & 0.141 & - \\
Dover & 0.2 & - \\
Knock Deep & 0.231 & 0.096 \\
Kentish Knock & 0.217 & 0.089 \\
Long Sand & 0.293 & 0.136 \\
\hline
\end{tabular}

\section{RESULTS}

The survey statistics strongly indicated that the distribution of the RTDs was highly clustered (Table 1). Approximately 7 to $8 \%$ fewer RTDs were observed during the visual surveys when maximum wave heights were higher than $1.2 \mathrm{~m}$ (Table 2). Both the high-resolution digital stills and visual survey platforms recorded similar overall patterns of diver distribution (Fig. S3 in the Supplement at www.int-res. com/articles/suppl/m542p221_supp.pdf).

The predicted semi-diurnal constituents' characteristics predicted by the local hydrodynamic model fitted well with the measurements, and their amplitudes were on average captured properly, with a maximum difference compared to the measurements of $0.06 \mathrm{~m}$, and phases fitted well with measurements (Table 3). Closer to the estuary, the predicted water levels by the local hydrodynamic model were satisfactory, both in terms of phase and amplitude (Table 4). The hydro- dynamic complexity within the outer Thames estuary induced by the presence of sand bars and channels was also well represented, including the asymmetric current pattern at Kentish Knock and the rotating flow at Long Sand, during the entire tidal cycle. The hydrodynamic model results stressed the influence of tidal currents on the conditions in the estuary, and documented significant changes in the current speeds and directions, as well as in the location of frontal zones through the tidal excursions. The post-processing of potential hydrodynamic habitat features revealed the existence of well-defined zones with frontal activity of limited spatial extent along the sand bars. Markedly lower frontal activity was estimated for the areas in the North Sea east of the outer Thames estuary. Strong horizontal fronts and eddy activity (vorticity) were identified during all 4 tidal current stages in zones with cross-frontal diameters of typically less than $5 \mathrm{~km}$ (Figs. 4 \& 5).

The GAM response curves were very similar in both data sets (Fig. S5 in the Supplement). The proportion of explained deviance was higher in the positive part of the model for the digital still aerial data, and the validation statistics were also in favour of both the presence/absence part and the positive part of the digital stills data (Table 5). The spatial patterns predicted on the basis of the visual and digital stills data in 2009-2010 were similar, but the model based on digital stills data produced higher densities (Fig. 6; Fig. S4 in the Supplement). An increasing gradient was seen in both model deployments from the west to the east, and both models displayed a patch of high densities at the eastern end of Long Sand and Kentish Knock. Higher densities recorded by the digital stills aerial surveys were expected, as more birds were counted by the digital stills surveys in comparison to the visual surveys. To visualise the agreement between the 2 models, the predicted probabilities and densities from the visual surveys were plotted against the digital stills surveys (Fig. 6). Although predicted probabilities were generally lower from the digital stills surveys, the predicted densities from the digital stills surveys were clearly higher (by a factor of 1 to 2.5) than those from the visual surveys. Spearman's correlation between the presence/absence predictions was 0.864 and between predicted densities 0.894. As the responses to the 

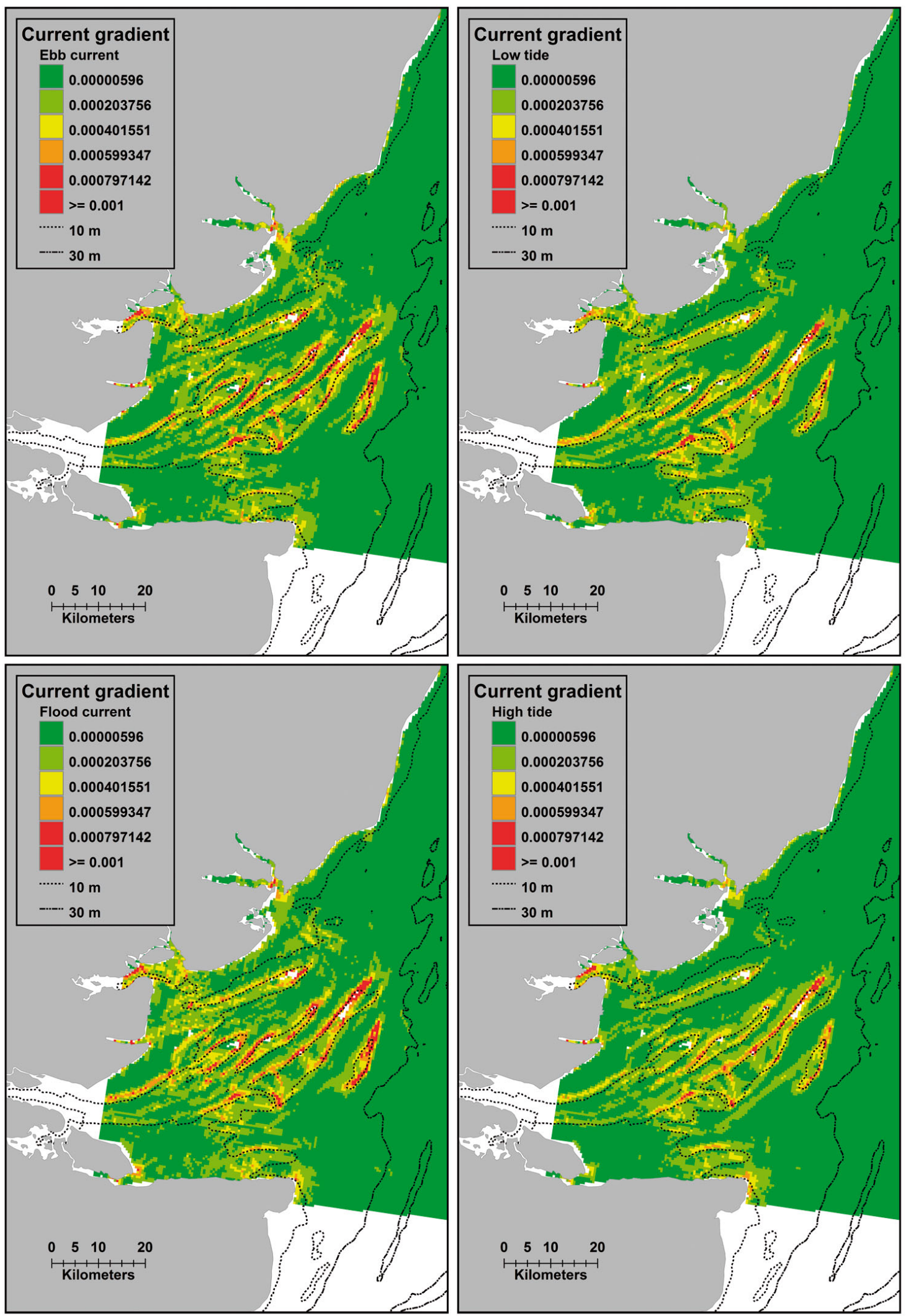

Fig. 4. Identified horizontal fronts (current gradients [see Table S1 in the Supplement at www.int-res.com/articles/suppl/ m542p221_supp.pdf]) during the 4 current scenarios. The 10 and $30 \mathrm{~m}$ depth contours are indicated 

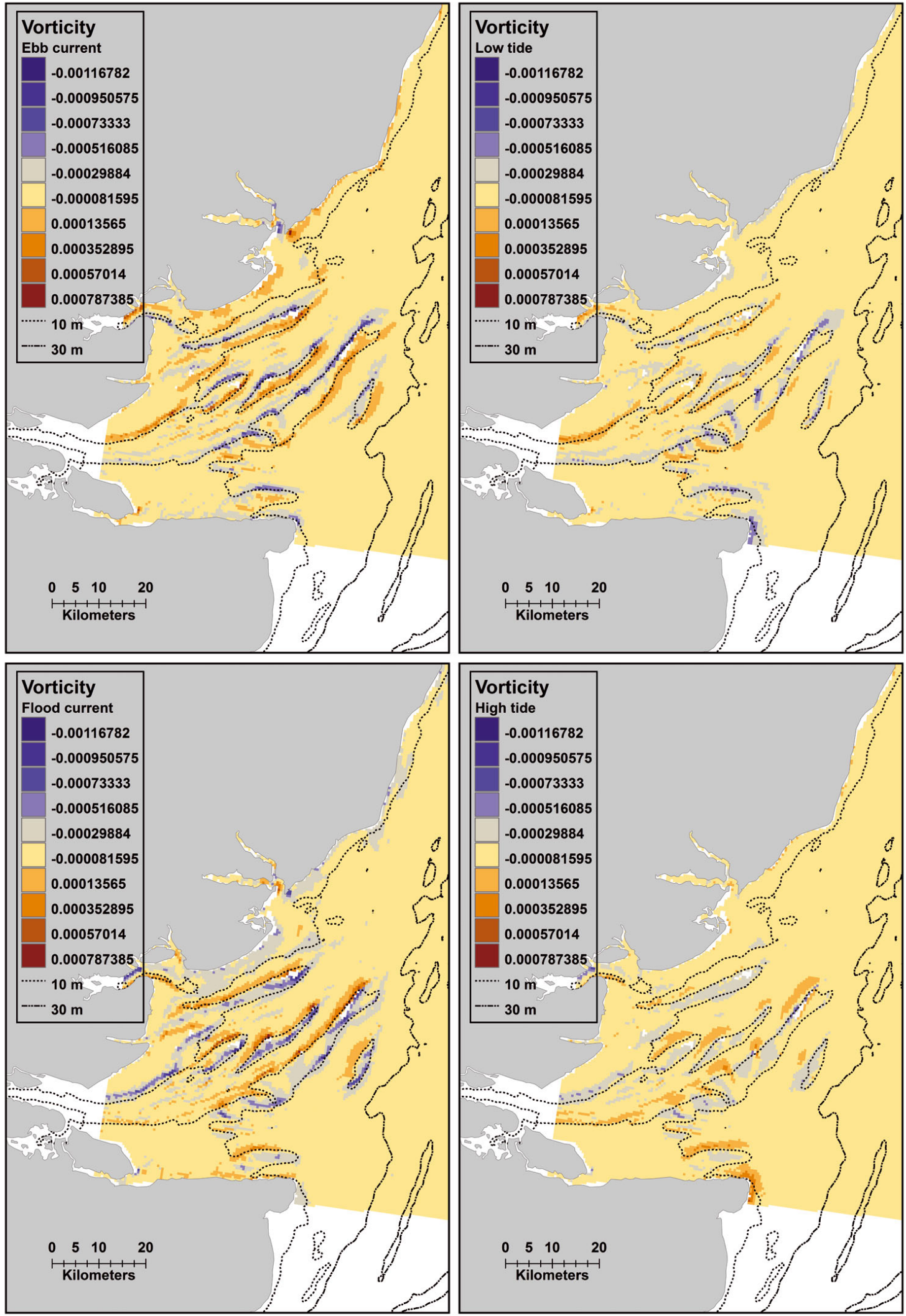

Fig. 5. Identified areas of eddy activity (vorticity [see Table S1 in the Supplement]) during the 4 current scenarios. The 10 and $30 \mathrm{~m}$ depth contours are indicated 
Table 5. Evaluation statistics for the 2 models based on aerial visual and digital stills data, respectively. Deviance explained (dev. exp.) for the presence/absence (P/A) part of the model and for the positive (density) part. AUC values are shown for the presence/absence part and the Spearman's rank correlation for the final combined model

\begin{tabular}{|lcccc|}
\hline & \multicolumn{2}{c}{ Dev. exp. } & AUC & $\begin{array}{c}\text { Spearman's rank } \\
\text { Correlation }\end{array}$ \\
& P/A & Positive & & 0.24 \\
Visual model & 36.8 & 25.7 & 0.694 & 0.44 \\
Digital stills model & 13.8 & 48.4 & 0.848 & \\
\hline
\end{tabular}

The positive parts of the 2 models representing the distribution of RTDs during strong tidal currents (flood/ebb current models) were quite different from phases 2 and 4 in the Supplement with weak tidal currents, and both differed from each other (Table 6, Figs. S6 \& S8 in the Supplement). In the phase 1 model, vertical velocity and current speed were important, thus the model indicated higher densities of RTDs in the outer

environmental data were also similar in the 2 sets of models, the inclusion of both data sets in further analyses of diver distribution in the estuary was justified, and increased the analytical sample size.

The results for the presence/absence part of all 4 distribution models were very similar and indicated that current speed, water level, vertical current velocity and seabed slope were important variables (Table 6, Figs. S6 to S9 in the Supplement). The models indicated a higher probability of presence of RTDs in areas with low water levels, moderate current speeds and high up/down-welling activity, and in sloped areas. In addition, the presence/absence part of the phase 3 model (flood current) indicated a higher probability of low ship density in offshore areas (Fig. S8 in the Supplement; Table 6). The positive parts of the 2 models representing the distribution of RTDs during weak tidal currents and slack water (low/high tide models) indicated high densities in shallow, slope areas with strong current gradients (Table 6, Figs. S7 \& S9 in the Supplement). Additionally, low current speed, high eddy activity, high slopes and low ship density were also important parameters in the positive part of the phase 4 model.
Thames estuary during ebb current in areas having low current speed and strong upwelling. In the phase 3 model, higher densities of RTDs were estimated in areas having high current speed and low density of ships. With the exception of the phase 2 model, for which moderate spatial autocorrelation was found in the 2 first lags in the positive part, all 4 stratified distribution models displayed low to very low spatial autocorrelation in the residuals of both model parts. This indicated that the models with the addition of $x$ - and $y$-coordinates reflected the variability in the observed densities of RTDs reasonably well. However, the proportion of deviance explained in the presence/absence parts was quite low (<20\%), while the proportion was moderate to high in the positive parts (31.3 to $65.6 \%$; Table 7 ).

In all current scenarios, the major part of the estuary was classified as either low or medium habitat suitability (Fig. 7). The lowest habitat suitability was indicated for the areas deeper than $20 \mathrm{~m}$, the shipping lanes and areas close to the coast. The suitable habitats were associated with the 3 southwest to northeast protruding sands-Sunk Sand, Long Sand and Kentish Knock - and the coastal area of Suffolk (to the
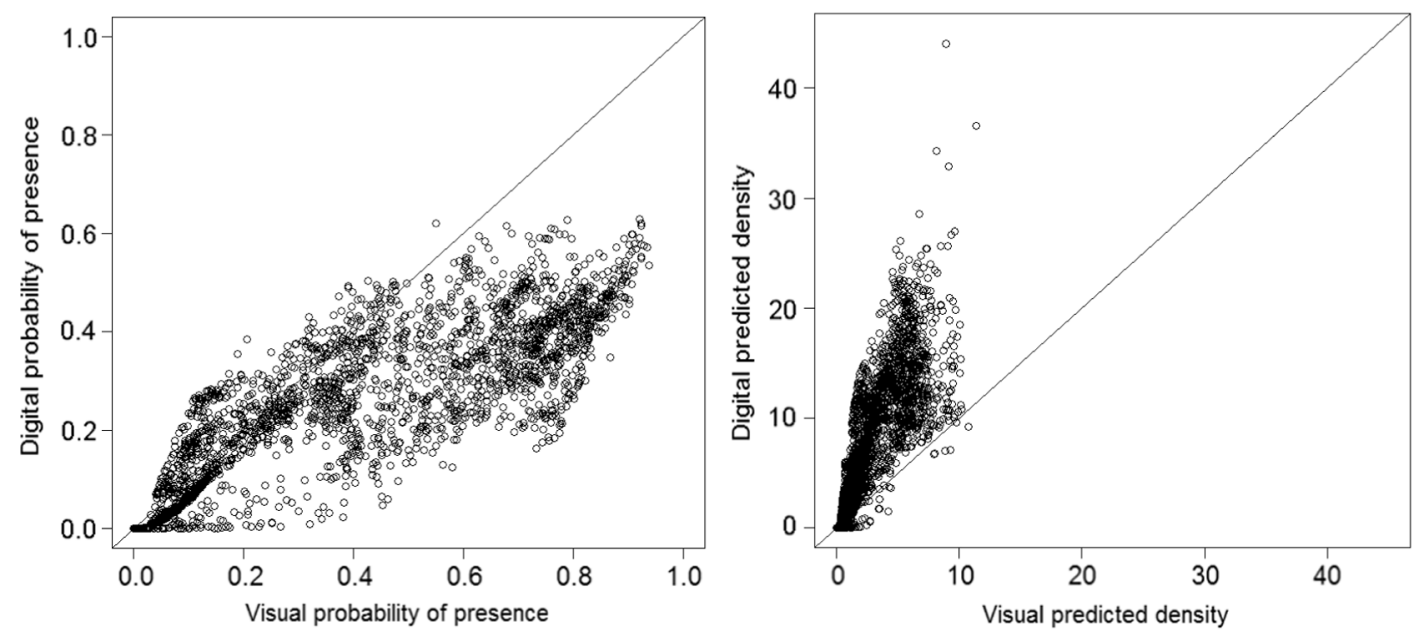

Fig. 6. Predicted probability of presence (left panel) and predicted density (right panel) on visual aerial data against the predicted probability/density on digital stills aerial data 

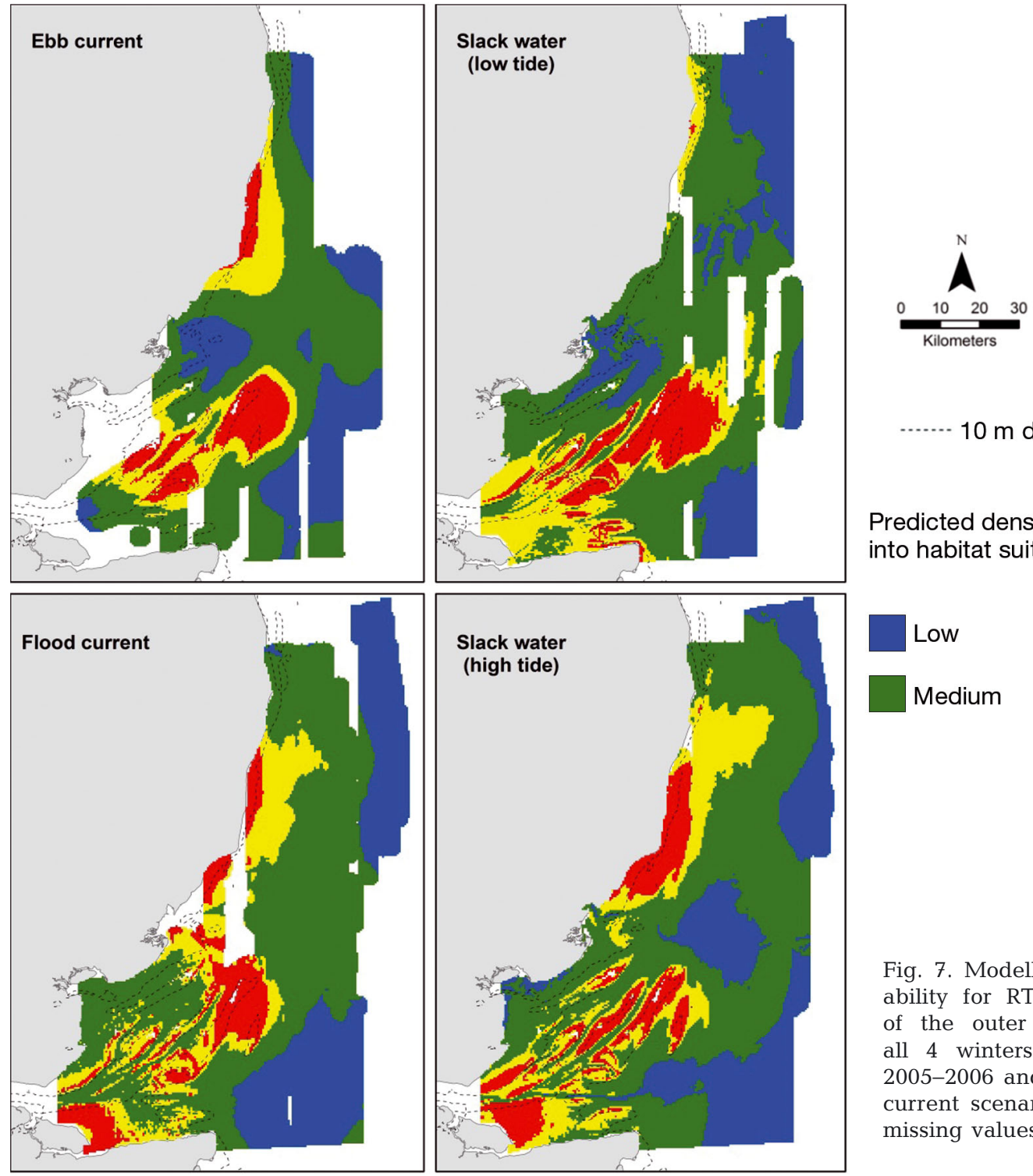

Predicted densities classified into habitat suitability

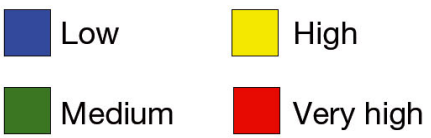

north) and Norfolk (to the south), as well as with the shallow area off the southwest coast of the estuary. The areas of suitable habitat change systematically with the flow regime. During the ebb current and low tide phase, areas in the southwestern part of the outer Thames estuary generally show low habitat suitability, while during flood current and high tide phases, prominent patches of very high habitat suitability are estimated in this part of the estuary. Therefore, a westward extension of the main distribution of RTDs in the estuary seems to take place during the 2 tidal phases dominated by westward-flowing currents. Superimposed on the east to west oscillation, changes in the north to south location of the most suitable habitats can be observed around the sand bars. During the flow phases with slack water (low/high tide), RTDs display a more concentrated distribution along the slopes of the sands than during the phases with stronger currents (ebb/flood current). The patch off the Suffolk-Norfolk coast is most extensive during flood current and high tide. Fig. 8 shows standard errors for the 4 stratified models. The errors are generally largest for the areas with higher diver densities; however, the depicted relative standard errors (\% of the predictions) are generally lower in the highdensity areas, and are generally below 30\%. The relative standard errors (\%) are generally highest in areas with very low densities, which means that the errors are also low and not very influential. The ebb current model had the highest proportion of explained variance in both the presence/absence part (19.3) and the positive part (65.6) (Table 7). The positive parts of 
Table 6. Smooth terms included in the 4 GAM models. Approximate significance and chi-squared $/ F$ statistics are shown. Variables not included in the final model are indicated with a dash. $w$ : vertical velocity; $x, y$ : geo graphical coordinates

\begin{tabular}{|c|c|c|c|c|}
\hline \multirow[t]{2}{*}{ GAM model } & \multicolumn{2}{|c|}{ Presence/absence } & \multicolumn{2}{|c|}{ Positive density } \\
\hline & Chi-squared & $\mathrm{p}$ & $F$ & $\mathrm{p}$ \\
\hline \multicolumn{5}{|l|}{ Ebb current } \\
\hline$w$ & 16.14 & $<0.01$ & 6.176 & 0.01 \\
\hline Current speed & 28.57 & $<0.01$ & 43.464 & $<0.01$ \\
\hline Vorticity $^{2}$ & - & - & - & - \\
\hline Current gradient & - & - & - & - \\
\hline Water level & 20.13 & $<0.01$ & - & - \\
\hline Slope & - & - & - & - \\
\hline Ship densities & - & - & - & - \\
\hline Land 5 km & - & - & - & - \\
\hline$x, y$ & 508.86 & $<0.01$ & 36.225 & $<0.01$ \\
\hline \multicolumn{5}{|l|}{ Low tide } \\
\hline$w$ & - & - & - & - \\
\hline Current speed & 33.17 & $<0.01$ & 2.692 & 0.04 \\
\hline Vorticity $^{2}$ & - & - & - & - \\
\hline Current gradient & & & 3.532 & 0.03 \\
\hline Water level & 34.47 & $<0.01$ & 10.402 & $<0.01$ \\
\hline Slope & 18.18 & $<0.01$ & 5.142 & $<0.01$ \\
\hline Ship densities & - & - & - & - \\
\hline Land 5 km & - & - & - & - \\
\hline$x, y$ & 343.12 & $<0.01$ & 12.766 & $<0.01$ \\
\hline \multicolumn{5}{|l|}{ Flood current } \\
\hline$w$ & 47.955 & $<0.01$ & 4.308 & $<0.01$ \\
\hline Current speed & - & - & 24.445 & $<0.01$ \\
\hline Vorticity $^{2}$ & - & - & - & - \\
\hline Current gradient & - & - & - & - \\
\hline Water level & 19.231 & $<0.01$ & - & - \\
\hline Slope & 6.342 & 0.01 & - & - \\
\hline Ship densities & - & - & 8.563 & $<0.01$ \\
\hline Land $5 \mathrm{~km}$ & - & - & - & - \\
\hline$x, y$ & 241.165 & $<0.01$ & 13.106 & $<0.01$ \\
\hline \multicolumn{5}{|l|}{ High tide } \\
\hline$w$ & - & - & - & - \\
\hline Current speed & 70.957 & $<0.01$ & 16.580 & $<0.01$ \\
\hline Vorticity $^{2}$ & - & - & 4.026 & $<0.01$ \\
\hline Current gradient & - & - & 7.065 & $<0.01$ \\
\hline Water level & 32.070 & $<0.01$ & 7.605 & $<0.01$ \\
\hline Slope & 8.624 & $<0.01$ & 4.193 & 0.01 \\
\hline Ship densities & 5.334 & 0.03 & 6.752 & $<0.01$ \\
\hline Land 5 km & 17.250 & $<0.01$ & - & - \\
\hline$x, y$ & 272.004 & $<0.01$ & 10.419 & $<0.01$ \\
\hline
\end{tabular}

Table 7. Evaluation statistics of the 4 GAM models. Deviance explained (dev. exp.) for the P/A part of the model and for the positive density part. AUC is the evaluation results for the P/A part and the Spearman's rank correlation is the evaluation of the final combined model

\begin{tabular}{|lcccc|}
\hline Model & \multicolumn{2}{c}{ Dev. exp. } & AUC & $\begin{array}{c}\text { Spearman's } \\
\text { rank }\end{array}$ \\
& P/A & Positive & correlation & \\
\hline Ebb current & 19.3 & 65.6 & 0.768 & 0.261 \\
Low tide & 14.8 & 45.1 & 0.749 & 0.239 \\
Flood current & 9.39 & 41.6 & 0.731 & 0.195 \\
High tide & 10.5 & 31.3 & 0.746 & 0.232 \\
\hline
\end{tabular}

all 4 models had generally much higher explained variances. The area under the curve (AUC) values indicate the models are capable of distinguishing presence from absence about $75 \%$ of the time, which is quite low but acceptable, given the high resolution of the model. The Spearman's correlation of the combined models indicates that there is a clear agreement between predicted and observed values (Table 7 ).

\section{DISCUSSION}

Despite the fact that the temporal overlap of the comparative surveys was relatively coarse (within the same month), similar density gradient patterns were obtained during the comparative surveys, and responses to hydrodynamics were also similar. In addition, the results clearly documented that digital aerial surveys generate higher densities of RTDs than visual aerial surveys. This difference is probably a function of smaller sampling bias and higher sampling resolution obtained in digital stills surveys (Buckland et al. 2012). Visual surveys are normally undertaken at an altitude of $76 \mathrm{~m}$, whereas digital aerial surveys are carried out at an altitude typically 4 to 6 times higher. This difference means that response movements of sensitive species such as RTDs to the approaching survey aircraft are more likely to occur during visual surveys, which may introduce bias with respect to false negative observations (Buckland et al. 2012). False negative observations due to diving birds are still an issue for both survey platforms. Moreover, every observed bird in a high-resolution digital image can be counted and time spent determining its identification, rather than the count and identification inevitably being an approximation of what the visual observer sees. Together with the comparative results from Buckland et al. (2012) for the common scoter Melanitta nigra, these results point at digital surveys as an improved method for unbiased aerial surveys of the more difficult and sensitive species of seabirds at sea. 

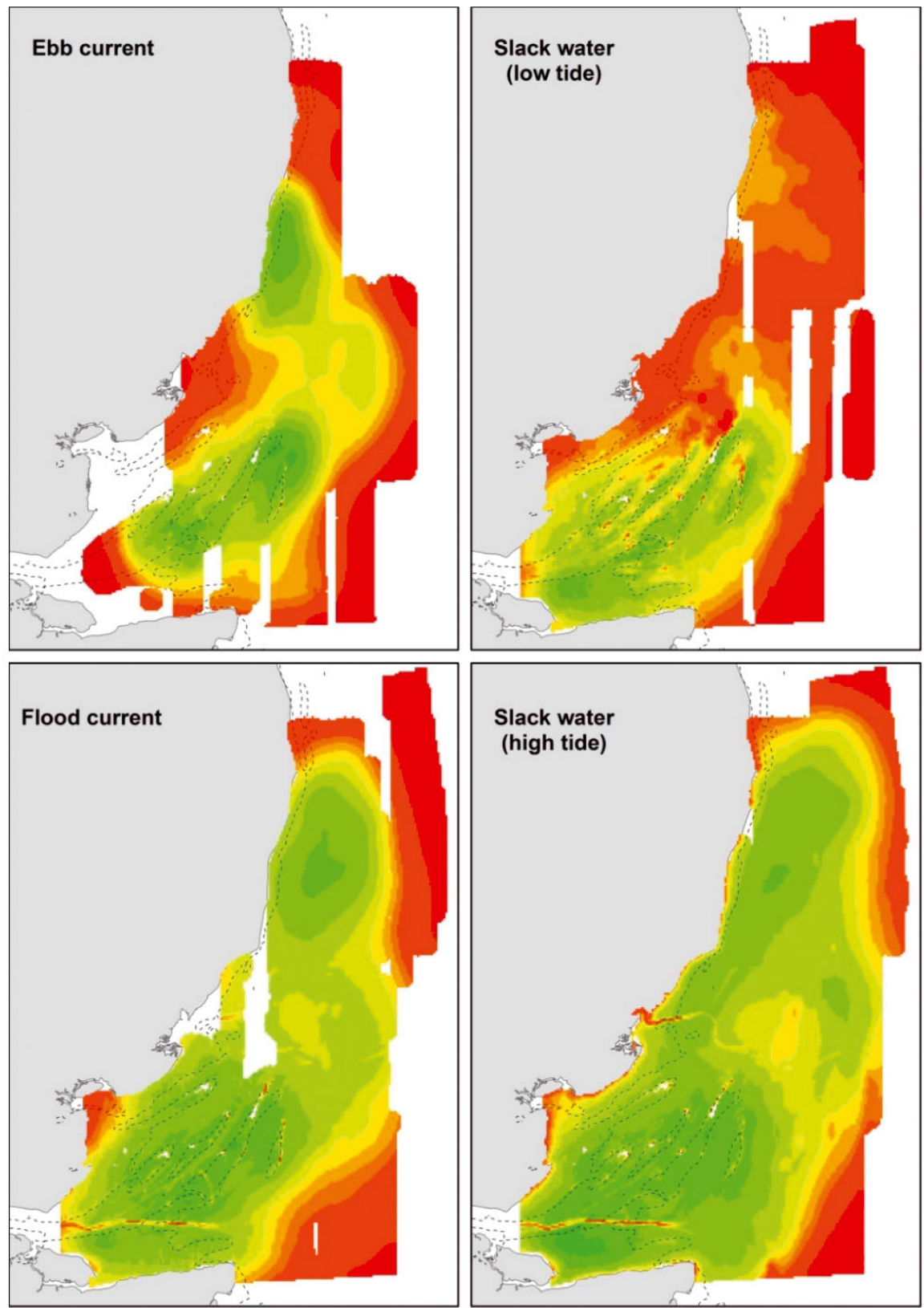

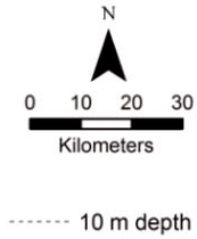

\section{Relative (\%) SEs for predicted densities}

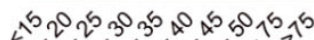

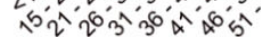

Fig. 8. Relative standard errors (\% of the predictions) for the combined predictions of the 4 GAMs. White areas indicate missing values. The spatial resolution is $500 \mathrm{~m}$
Both the pure tidal propagation along the east English coast and the interaction between steep bathymetry gradients and large tidal range varying across the area needed to be resolved by the local hydrodynamic model in order to sufficiently describe the complex hydrodynamics in the outer Thames estuary area. The model validations showed that both features were captured satisfactorily by the model design. High resolution turned out to be important in relation to identified main predictor variables, especially horizontal fronts during periods dominated by slack water at high and low tide, when RTDs are most concentrated over limited space. The design of the hydrodynamic modelling scenarios successfully resolved the major oscillations in the distribution of RTDs in the estuary in response to the dynamics of fine-scale hydrodynamic features, especially fronts. These findings are in line with the literature on the biological oceanography of seabirds, which unambiguously points at concentrations of piscivorous species at small-scale hydrodynamic features like bathymetry- and tidally steered frontal structures (Iverson et al. 1979, Schneider \& Duffy 1985, Schneider 1990). The general interpretation of these affinities is the enhancement of the probability of prey encounter, which greatly maximizes predators' foraging success (Schneider \& Duffy 
1985, Skov \& Prins 2001, Fauchald et al. 2011). In comparison with higher-frequency oceanographic dynamics, the metastable fronts with lower-frequency oscillations can be readily identified from fine-scale hydrodynamic models like the one implemented. Thus, accurate marine distribution models for seabirds will have the potential to resolve key habitats, and describe the changes in distributions in response to the oscillation of the frontal structure in question. At the same time, it is worth pointing out the moderate fit of the presence/absence parts of the models, and the fact that both the coverage across the period of investigation and the spatial match between the distribution of feeding seabirds and oceanographic dynamics can be improved. Here, specifically the inclusion of behavioural details during both aerial methods would enable the analytical distinction between flying, onfeeding and feeding birds. Such details would typically require ship-based observations. Furthermore, no evaluation of the effect of spatial scale on the strength of the association of RTDs with oceanographic structures was undertaken. As the analyses were made at the highest possible spatial resolution $(500 \mathrm{~m})$, it is likely that spatial mismatches are present in the data. Hence, the strength of oceanographic associations may increase as the scale of analysis increases.

The validation results for the dynamic distribution models applied in this study show that the 4 stratified models were capable of describing the distributional dynamics of RTDs during the 4 main tidal current phases in the outer Thames estuary. The complex oscillation of RTDs between these current phases reflects combined longitudinal-latitudinal changes in hydrodynamics, especially currents and fronts, which were readily identified from the summaries of the hydrodynamic model. Despite a spatial resolution of $500 \mathrm{~m}$ the models were, based on AUC statistics, capable of distinguishing presence from absence about $75 \%$ of the time, and the predicted density of the RTDs agreed closely with the observed values. These results all indicate that the 2-step model design and the assimilation of post-processed dynamic habitat variables from a well-calibrated local hydrodynamic model made it possible to strike a balance between high model parsimony and accuracy.

In the past, most marine distribution models have been undertaken using static variables, partly due to the limited availability of dynamic predictor variables and assumptions that pelagic habitats are relatively stable. Our study in the outer Thames estuary has documented that, with high-resolution survey data and dynamic habitat variables, changes in the distribution of marine animals can be tracked in real time with sufficiently detailed predictors and survey data. The combination of dynamic distribution modelling and digital high-resolution aerial survey methods seems to have the potential to pave the way for assessments of the status and changes in distributions and local population sizes of marine species on the basis of more realistic quantitative descriptions of their natural habitats (Embling et al. 2012). Spatially refined assessments of habitat displacement of species sensitive to the presence of offshore wind farms and other marine infrastructures will enhance both the planning and environmental management of these developments. In addition, designation of marine protected areas will potentially benefit from the development of fine-scale dynamic distribution models and availability of digital aerial survey data, as boundaries of areas of persistent high densities can be identified with less error.

Acknowledgements. The research was funded by London Array Ltd., a consortium of the 3 renewable energy companies DONG, EON and Masdar.

\section{LITERATURE CITED}

Bailey H, Thompson PM (2009) Using marine mammal habitat modelling to identify priority conservation zones within a marine protected area. Mar Ecol Prog Ser 378: 279-287

Buckland ST, Burt ML, Rexstad EA, Mellor M, Williams A, Woodward R (2012) Aerial surveys of seabirds: the advent of digital methods. J Appl Ecol 49:960-967

- Cama A, Abellana R, Christel I, Ferrer X, Vieites DR (2012) Living on predictability: modelling the density distribution of efficient foraging seabirds. Ecography 35:912-921

Elith J, Graham CH, Anderson RP, Dudík M and others (2006) Novel methods improve prediction of species' distributions from occurrence data. Ecography 29:129-151

Embling CB, Illian J, Armstrong E, van der Kooij J, Sharples J, Camphuysen CJ, Scott BE (2012) Investigating finescale spatio-temporal predator-prey patterns in dynamic marine ecosystems: a functional data analysis approach. J Appl Ecol 49:481-492

Fauchald P, Skov H, Skern-Mauritzen M, Hausner VH, Johns D, Tveraa T (2011) Scale-dependent response diversity of seabirds to prey in the North Sea. Ecology 92: 228-239

Follestad A (1990) The pelagic distribution of little auk Alle alle in relation to a frontal system off central Norway, March/April 1988. Polar Res 8:23-28

> Fox AD, Desholm M, Kahlert J, Christensen TK, Petersen IK (2006) Information needs to support environmental impact assessment of the effects of European marine offshore wind farms on birds. Ibis 148:129-144

- Guisan A, Zimmermann NE (2000) Predictive habitat distribution models in ecology. Ecol Model 135:147-186

Hastie T, Tibshirani R (1990) Generalized additive models. Chapman \& Hall, London

Iverson RL, Coachman LK, Cooney RT, English TS and others (1979) Ecological significance of fronts in the 
southeastern Bering Sea. In: Livingston RL (ed) Ecological processes in coastal and marine systems. Plenum Press, New York, NY, p 437-465

Kinder TH, Hunt GL Jr, Schneider D, Schumacher JD (1983) Correlations between seabirds and oceanic fronts around the Pribilof Islands, Alaska. Estuar Coast Shelf Sci 16:309-319

Le Pape O, Guérault D, Désaunay Y (2004) Effect of an invasive mollusc, American slipper limpet Crepidula fornicata, on habitat suitability for juvenile common sole Solea solea in the Bay of Biscay. Mar Ecol Prog Ser 277: 107-115

MacLeod CD, Zuur AF (2005) Habitat utilisation by Blainville's beaked whales off Great Abaco, northern Bahamas, in relation to seabed topography. Mar Biol 147:1-11

Maxwell DL, Stelzenmüller V, Eastwood PD, Rogers SI (2009) Modelling the spatial distribution of plaice (Pleuronectes platessa), sole (Solea solea) and thornback ray (Raja clavata) in UK waters for marine management and planning. J Sea Res 61:258-267

Pendleton DE, Sullivan PJ, Brown MW, Cole TVN and others (2012) Weekly predictions of North Atlantic right whale Eubalaena glacialis habitat reveal influence of prey abundance and seasonality of habitat preferences. Endang Species Res 18:147-161

Potts JM, Elith J (2006) Comparing species abundance models. Ecol Model 199:153-163

R Development Core Team (2004) R: a language and environment for statistical computing. R Foundation for Statistical Computing, Vienna. Available at http://www.Rproject.org

Rasmussen EB (1991) A finite difference scheme for three dimensional modelling of fluid dynamics. Proc IAHR, World Congress (International Association for HydroEnvironment Engineering and Research), Madrid 1: 339-348

reNews (2014) ReNews Global Offshore Report 2014. Renews Limited, Winchester

Robinson LM, Elith J, Hobday AJ, Pearson RG, Kendall BE, Possingham HP, Richardson AJ (2011) Pushing the limits in marine species distribution modelling: lessons from the land present challenges and opportunities. Glob Ecol Biogeogr 20:789-802

Schneider DC (1982) Fronts and seabird aggregations in the

Editorial responsibility: Jacob González-Solís,

Barcelona, Spain southeastern Bering Sea. Mar Ecol Prog Ser 10:101-103 Schneider DC (1990) Seabirds and fronts - a brief overview. Polar Res 8:7-22

Schneider DC, Duffy DC (1985) Scale-dependent variability in seabird abundance. Mar Ecol Prog Ser 25:211-218

Schneider DC, Hunt GL Jr (1982) Carbon flux to seabirds in waters with different mixing regimes in the southeastern Bering Sea. Mar Biol 67:337-344

Skov H, Prins E (2001) Impact of estuarine fronts on the dispersal of piscivorous birds in the German Bight. Mar Ecol Prog Ser 214:279-287

- Skov H, Durinck J, Bloch D (2003) Habitat characteristics of the shelf distribution of the harbour porpoise (Phocoena phocoena) in the waters around the Faroe Islands during summer. NAMMCO Sci Publ 5:31-40

Skov H, Heinänen S, Hansen DA, Ladage F, Schlenz B, Zydelis R, Thomsen F (2014) Marine habitat modelling for harbour porpoises in the German Bight. In: Federal Maritime and Hydrographic Agency (BSH), Federal Ministry for the Environment, Nature Conservation and Nuclear Safety (BMU). Ecological research at the offshore windfarm Alpha Ventus - challenges, results and perspectives. Springer Spektrum, Wiesbaden, p 151-171

Sørensen JVT, Madsen H, Madsen H (2004) Efficient Kalman filter techniques for the assimilation of tide gauge data in three dimensional modeling of the North Sea and Baltic Sea system. J Geophys Res 109:C03017, doi:10.1029/2003JC002144

Stefánsson G (1996) Analysis of groundfish survey abundance data: combining the GLM and delta approaches. ICES J Mar Sci 53:577-588

Thomas L, Buckland ST, Rexstad EA, Laake JL and others (2010) Distance software: design and analysis of distance sampling surveys for estimating population size. J Appl Ecol 47:5-14

> Webley JAC, Mayer DG, Taylor SM (2011) Investigating confidence intervals generated by zero-inflated count models: implications for fisheries management. Fish Res 110:177-182

Wood SN (2006) Generalized additive models: an introduction with R. Chapman \& Hall, London

Wood SN, Augustin NH (2002) GAMs with integrated model selection using penalized regression splines and applications to environmental modeling. Ecol Model 157:157-177

Submitted: June 8, 2015; Accepted: November 24, 2015

Proofs received from author(s): January 9, 2016 